\title{
ExtraterRestres en el imaginARio NeW AGE: REDES DE ESPIRITUALIDAD Y UTOPÍA DESDE San Cristóbal de Las Casas, Chiapas
}

\author{
Astrid Maribel Pinto Durán \\ Martín de la Cruz López Moya
}

Resumen: Una alusión constante de redes considerads New Age es la existencia de extraterrestres y el vínculo que sostienen haber desarrollado con ellos. Este tema es parte constitutiva de un trabajo imaginativo utópico producido por una red que se autonombra Guerreros de Luzy defiende el advenimiento de una nueva era. El extraterrestre funge como alteridad, como un punto de ruptura epistemológica desde el cual se juzga el mundo en que vivimos. El vínculo más importante entre los integrantes de esta red lo constituye el trabajo de la imaginación, indisociable de medios de comunicación como la Internet, la música o el cine. El presente es un estudio interpretativo de la labor de una red que intenta imaginar, con un lenguaje metafórico, otras posibilidades de realidad.

Palabras clave: utopía, imaginación, extraterrestres, Guerreros de Luz, new age, redes, metáforas.

Enviado a dictamen: 12 de octubre de 2011

Aprobación: 29 de noviembre de 2011

Revisiones: 1

Dra. Astrid Maribel Pinto Durán, doctora en Antropología. Investigadora del Centro de Estudios Superiores de México y Centroamérica de la Universidad de Ciencias y Artes de Chiapas. Cuerpo académico "Sociedad y Culturas en Fronteras". Línea de investigación: Globalización y Culturas Urbanas.

Mtro. Martín de la Cruz López Moya, maestro en Antropología. Investigador del Centro de Estudios Superiores de México y Centroamérica de la Universidad de Ciencias y Artes de Chiapas. Cuerpo académico "Sociedad y Culturas en Fronteras". Línea de investigación: Globalización y Culturas Urbanas.
Abstract: A constant reference considered New Age networks is the existence of aliens and the link that say they have developed with them. This topic is part and parcel of a utopian imaginative work produced by a network calling itself Warriors of Light and defends the advent of a new era. The alien serves as an otherness, an epistemological break point from which to judge the world in which we live. The most important link between the members of this network is provided by the work of the imagination inextricably linked to the media as the Internet, music or movies. This is an interpretive study of the work of a network that tries to imagine, with a metaphorical language, other possibilities of reality.

Keywords: utopia, imagination, aliens, warriors of light, new age, networks, metaphors.

\section{Introducción}

S upuestos seres de otros planetas, ampliamente referidos como extraterrestres en el lenguaje cotidiano, aparecen desde hace ya varias décadas en las pantallas del cine como protagonistas, a veces antagónicos, a veces como seres sabios y amigables con la humanidad. Entre uno de los ejemplos más recientes se encuentra la cinta Avatar, un film que lleva hasta sus últimas consecuencias el tono utópico con el que 
se presentan las posibilidades de otras formas de vida transplanetarias. Pero, además, el tema de seres no terrícolas ha desplegado la fantasía en las canciones y en la literatura populares, así como en programas de televisión o en revistas sobre el tema, permeando también las conversaciones informales o callejeras. El interés por los extraterrestres y la discusión sobre la posibilidad de vida no humana en el universo alcanzó un punto álgido, incluso, en el medio científico, con la declaración del físico Stephen Hawking, quien aceptó en el canal de televisión Discovery Channel la probabilidad de la existencia de vida en otros rumbos del universo.

No pretendemos dar cuenta de la extensa variedad de creencias, imaginarios y debates científicos o seudocientíficos sobre los extraterrestres, sino interpretar la defensa de la vida extraplanetaria por parte de los Guerreros de Luz, red de espiritualidad a la cual haremos referencia en este artículo, quienes sostienen el fin de un ciclo como parte de un imaginario que intenta irrumpir y destrabar los candados de la "realidad", aquella en la que, plantean, estamos atrapados y de la cual hay que liberarse.

Quienes se interesan en el estudio de grupos o redes que comparten y defienden el advenimiento de una nueva era han tenido que toparse, tarde o temprano, con la constante alusión no sólo a la existencia de los extraterrestres, sino al vínculo y a la comunicación que los integrantes de estas redes sostienen haber desarrollado con seres de otras galaxias, venidos de los puntos más diversos del cosmos. ${ }^{1}$

En los trabajos que dan cuenta de las tendencias generales del movimiento New Age, el dato es presentado como parte de un listado de características que incluyen, además de la creencia en los extraterrestres, la opción por la medicina alternativa, el cuidado del cuerpo, o el bricolage de creencias extraídas de las más disímiles tradiciones, por poner algunos ejemplos. El informe sobre esta recurrente mención a los extraterrestres es propuesto como un dato curioso, aunque poco merecedor de nuestra atención, por tratarse de "una ocurrencia ingenua proveniente de gente que, por alguna razón, parece haber perdido la cabeza", como lo definió un colega antropólogo en una charla informal.

Nos interesa aquí destacar la importancia que han adquirido estos "seres provenientes de otros planetas" como parte constitutiva de un trabajo imaginativo que se esfuerza por revertir el actual ordenamiento humano y planetario. Ordenamiento que, según los adeptos que defienden el fin de una era y el comienzo de otra, ha sido propiciado por el desarrollo científico. Reflexionaremos, entonces, sobre el virtual surgimiento de un nuevo paradigma que intenta legitimarse como científico-espiritual, y que, por lo mismo, se erige sobre otros parámetros de racionalidad. Dichos parámetros dan cabida a la posibilidad de una presencia extraterrestre entre los humanos y a la creciente interacción con ellos.

Hemos procurado en todo momento un diálogo respetuoso con este despliegue de la imaginación, a través de una escucha atenta de sus propios argumentos, pues consideramos que para comprenderlos es necesario detenerse, suspender nuestros prejuicios y, tal como lo propuso alguna vez Gadamer (1977, 2002), admitir que el otro puede tener razón. No se trata de emitir un juicio de valor para desmentirlos o junto con ellos defender la existencia de estos seres, sino de un ejercicio de diálogo, de comprensión.

Nuestros principales argumentos en este diálogo son, en primer término, que este imaginario construido en torno a los extraterrestres constituye no un elemento aleatorio, sino una clave para comprender en general el sentido de este imaginario. Sostenemos que, por la forma en que son imaginados los lazos e interacciones con los extraterrestres y el propio universo, asistimos a la elaboración de una utopía, la utopía de un imaginario en red, para ser más precisos, una red que se teje con hilos humanos, pero también extraterrestres, divinos y tecnológicos. 
Desde esta óptica el cosmos, poblado supuestamente por estos seres, constituye un espacio desde el cual se juzga y deslegitima el actual orden civilizatorio. Junto con los "hermanos de las estrellas", esto es, los extraterrestres benévolos que transmiten sus enseñanzas, y demás "seres de luz" constituidos por ancestros, divinidades, ángeles o hadas, que en este caso son imaginados con valores y actitudes humanas, los Guerreros de Luz se afanan en construir una otredad que haga las veces de un sitio inexistente tipo utopía una otredad recreada para generar una ruptura epistemológica. ${ }^{2}$ Como lo propone Paul Ricoeur (2002), por tratarse de un trabajo de la imaginación, la trasgresión comienza por el lenguaje mismo. ${ }^{3}$

Otra propuesta de este artículo es precisamente que el lenguaje recreado y por momentos extraño que dichos adeptos emplean para referirse a este universo poblado de presencias es altamente metafórico y que son precisamente esas metáforas las pistas para comprender la naturaleza de este trabajo de la imaginación. Las principales redes metafóricas que indican esta labor imaginaria son la propia noción de red, concepción e imagen central que nos remite al universo poblado por hermanos de las estrellas; la de realidad y la de energía, conceptos metaforizados y asociados a la luz.

Por último, y quizá esta sea la hipótesis que atraviesa todas las demás, sostenemos que el lazo más importante entre los integrantes de esta red telemática lo constituye el trabajo de la imaginación; que no existe, incluso, alguna liga más notable en sus relaciones que la confección de un imaginario, en este caso utópico, cuya pretensión es actuar sobre la realidad para transformarla. ${ }^{4}$ Lo que se comparte es no sólo un imaginario, sino la acción constante de crear ese imaginario. Es el trabajo de la imaginación, es su construcción lo que crea las ligaduras y las interacciones, cuando éstas logran darse, incluso, cara a cara. De ahí la importancia de comprender esta labor de la imaginación en sus propios términos: traducir sus imágenes nodales es comenzar a entenderla. ${ }^{5}$

\section{Guerreros de Luz: una ramificación de la red}

En el apartado anterior nos referimos, en términos muy generales, a los movimientos New Age. Bastante se ha cuestionado este término como herramienta heurística, pero concedámosle, al menos, la capacidad para situarnos de inmediato sobre el terreno pantanoso formado por una multitud de caminos, búsquedas individuales y grupales en distintas tradiciones, religiosidades reinterpretadas o reformuladas, formas de asociación inéditas articuladas por una idea en común: la de estar presenciando el fin de una época y el comienzo de otra. Sin embargo, por sí sola esta creencia no es suficiente como para establecer generalizaciones, debido a la ya conocida diversificación, en sus formas y contenidos, no sólo de las dinámicas sino, sobre todo, de la labor imaginativa de estas asociaciones. Nos centraremos, entonces, en uno de los bamboleos de la red, cuyo movimiento va hacia una dirección, hacia un sentido. Vamos a referirnos a una asociación que a sí misma suele llamarse red. El trabajo de imaginación de esta red genera sus formas de acción, de congregación, así como sus propias dinámicas y estrategias de asociación.

Quienes están enlazados por este imaginario suelen autonombrarse Guerreros de Luz y comparten la idea, afín a múltiples grupos o asociaciones espirituales, de que presenciamos los albores de una nueva era. Se trata de una red formada principalmente por personas que han cursado carreras universitarias -por lo tanto, profesionistas de las más variadas formaciones-, pero también por estudiantes, viajeros, monjas, amas de casa y, sobre todo, sanadores alternativos. Los más avanzados, quienes han caminado más por las sendas de la espiritualidad, es decir, quienes han incursionado en el aprendizaje de alguna tradición, se convierten en los dinamizadores de la red: los maestros, guías espirituales, muchos considerados chamanes, algunos de los cuales afirman haber sido contactados por los extraterrestres o ser canalizadores de ángeles o deidades. 
Internet es el principal medio recurrido por los Guerreros de Luz, a través del cual comparten una extensa literatura que incluye mensajes, videos con temas de autoayuda, textos extensos que pretenden ser canalizaciones de seres más evolucionados que los humanos y que, en general, constituyen en sí mismos evaluaciones del estado actual de nuestras instituciones. La información compartida circula, sobre todo, por correo electrónico. Los mensajes son reenviados de Guerrero a Guerrero y quien se interesa por conocer la procedencia de dichos mensajes puede seguir, con suerte, la trayectoria continuada por estos reenvíos, a partir de la información que va quedando registrada tras el envío de cada mensaje. Entre más hacia atrás se observa la trayectoria de un mensaje, más difícil es reconocer el nombre de algún conocido, pues la red es extensa y no todos sus integrantes han tenido algún encuentro cara a cara o algún intercambio directo por Internet u otro medio.

Pudimos tener acceso a la información que circula por la red, porque nos hicimos parte de ella. Durante algunos eventos cara a cara realizados con algunos de los integrantes de esta red en San Cristóbal de Las Casas, Chiapas, pudimos intercambiar nuestras direcciones electrónicas. De inmediato, nuestras bandejas de entrada se poblaron con mensajes provenientes de los Guerreros de Luz, a tal punto que cada mañana debíamos dedicar varias horas a su revisión y lectura.

Muchos de estos Guerreros de Luz viven o tienen nexos importantes con esta ciudad, caracterizada ahora por un flujo significativo de ofertas de espiritualidad y técnicas de sanación que, unidas a la diversificación religiosa de sectores más fijos de la población, contribuyen a la configuración de una urbanidad compleja, haciendo de ella un auténtico nicho multiforme capaz de acoger las más disímiles demandas de religiosidad, de tradición (incluida, entre muchas otras, la maya), así como técnicas corporales y de sanación alternativa.
La red trabaja por pequeñas asociaciones. Cada asociación se acoge a alguna tradición o técnica espiritual. La red no es ni totalmente telemática, ni totalmente territorial. Para ser más asertivos, diríamos que conoce momentos de proxémica durante los cuales algunos de sus integrantes logran relaciones y acciones localizadas, incluso, como lo proponen, con extraterrestres y otros seres venidos del espacio sideral. Como la red es amplia, sus hilos se van tejiendo con las enseñanzas de múltiples maestros, portadores de diversas tradiciones. Pero la tradición es aquí reimaginada. Los extraterrestres así imaginados, por ejemplo, serían portadores de sus propias tradiciones, en algunos casos, infinitamente más desarrolladas que las nuestras. Y si la tradición como categoría sugiere un origen auténtico, asentir que los extraterrestres tienen sus propias tradiciones y que en cierto sentido somos herederos de ellas, es imaginar una humanidad de origen estelar.

\section{Hijos de las estrellas. Nuestro origen estelar}

Todo ser sobre el planeta proviene de algún otro lugar de la Galaxia o el Universo, nadie es del Planeta Tierra, nuestras Almas no fueron creadas aquí, todos venimos de otro tiempo y lugar, mi entendimiento es que todo el espíritu consciente en este Universo vino a través de agujeros negros desde otros Universos. Todos nosotros somos muy viejos, no tenemos edad, no fuimos creados con este universo, sino que vinimos a éste a través de los agujeros negros desde otros lugares para continuar evolucionando en este universo.

Alex Collier

Antes de considerar los discursos sobre extraterrestres, a los cuales tuvimos acceso porque nos fueron compartidos por los mismos Guerreros de Luz en forma paulatina y a través de Internet, nos parece importante señalar que este imaginario sobre los hermanos de las estrellas es fomentado y construido, también, en los 
encuentros cara a cara entre algunos de los integrantes de la red. Durante nuestro trabajo de campo en San Cristóbal de las Casas, tuvimos la oportunidad de asistir a las sesiones de meditación en movimiento y a los talleres que ofrece uno de los maestros nodales de esta red. En las charlas de los asistentes, pero también durante los rituales, el tema de los extraterrestres aparecía una y otra vez casi obstinadamente.

En la cumbre de la montaña, donde este maestro imparte talleres durante los solsticios de verano e invierno, se aprende, sobre todo, el manejo de la energía con técnicas de movimiento que son presentadas como mayas-tibetanas. ${ }^{6}$ Estas enseñanzas van acompañadas de una ritualidad compleja. Durante cuatro días y tres noches no cesan las danzas, el sonido de los tambores, de los caracoles y las maracas; un aroma a incienso y copal invade ese rincón del bosque. Inmersos en un ambiente ritual, los Guerreros de Luz pueden intercambiar experiencias espirituales, pues muchos de ellos son portadores de otras tradiciones: tolteca, lakota, huichol, cristiana, budista, danzantes concheros o de la mexicanidad, y la lista es interminable.

Parte importante de esas experiencias compartidas verbalmente es el reconocimiento de haber presenciado, de alguna manera, a seres extraterrestres. Las conversaciones en torno a estas vivencias pueden durar horas. Lo que se cuenta es haber visto naves, haber reconocido a algún extraterrestre transfigurado en humano. También se considera que uno de los maestros que apoya estos talleres, un indígena seri, es un hermano de las estrellas", quien ha descendido a la tierra para ayudar al salto cuántico de la humanidad, del planeta. Se dice, incluso, que él sube con frecuencia a las naves extraterrestres. El propio maestro que convoca a estos talleres es considerado por sus adeptos como un ser de altísima frecuencia venido de otro planeta con el poder de desplazarse por varios dimensionales del cosmos. En términos generales, se considera que entre los maestros y guías espirituales que dinamizan la red, se encuentran muchos de origen estelar. Hay quienes dicen, incluso, que los terrícolas somos un implante, que venimos todos de distintos planetas. No existe un consenso. Muchas de las charlas son verdaderas controversias, donde se discute, al tiempo que se crea un imaginario nutrido de los documentos que circulan por Internet, acerca de las experiencias y las propias discusiones en torno a los seres siderales.

Las polémicas giran, sobre todo, en torno a la naturaleza de estos seres. Por ejemplo, durante un ritual que se realizó en las ruinas de Toniná, para celebrar el Año Nuevo maya, se realizó un encuentro ritual entre chamanes. Una de las asistentes, compañera de uno de los chamanes nodales de la red nos comentó:

Hubieron presencias luminosas y otras extrañas. Se filtró una mujer muy pálida y con una extraña energía. Estaba ahí para sacar información, para intervenir energéticamente. No era una hermana de las estrellas. Era un extraterrestre de los malos, de los que no quieren que evolucionemos. Rarísima.

Es decir, desde este punto de vista no todos los extraterrestres son buenos. Se considera, por ejemplo, que nuestro planeta ha sido conducido hasta este punto por los "grises", extraterrestres illuminatis infiltrados en los sistemas políticos y financieros, responsables de las guerras y el deterioro ecológico. Se está librando, entonces, una batalla entre estos seres y los "seres de luz". Los hermanos de las estrellas están apoyando a los humanos para liberarse de esta raza cósmica nociva, destructora. Pero la cruzada no es violenta. Se trata de activar en cada uno la luz, la capacidad de amar, de transmutarse en un ser de alta frecuencia. Ahora bien, ipor qué los hermanos de las estrellas están apoyando a los humanos en este combate? Según esta perspectiva, porque el holograma universal está en riesgo si la tierra se destruye y no logra cambiar su frecuencia. Nuestros hilos energéticos están unidos a todo cuanto existe en el universo, y salvarnos significa salvar al universo, la red interplanetaria. Además, se cree que 
algunos otros planetas en nuestra galaxia están en la misma condición y también están recibiendo ayuda. Otra razón expuesta, incluso con más frecuencia, es que no todos los extraterrestres tienen alma ni conocen las emociones. Los humanos tenemos un papel fundamental en el universo debido a esta capacidad para el amor, sentimiento indispensable en esta cruzada.

En el último taller al que asistimos, durante el solsticio de invierno, no ocurrió nada, no hubo enseñanzas por parte del maestro y una extraña tensión dominaba el ambiente. Se esperaba la llegada de los extraterrestres. En la noche del tercer día de taller, otro de los maestros de la red propuso una ceremonia en un tipi de origen dakota. Se encendieron varias pipas e inició el ceremonial entre oraciones, cantos y música.Se consideró que fue por ahí y durante esta ceremonia que descendieron los extraterrestres. Se trató de la llegada de la denominada Confederación Galáctica, guiada por altos mandos. El propósito del encuentro era realizar un pacto de colaboración y la instauración de nuevos códigos en nuestros registros de ADN. Estos registros fueron modificados con la finalidad de hacernos más aptos para esta cruzada, para el "salto cuántico". No todos se enteraron de este hecho, algunos comentaron que habían sentido su presencia como en un estado de somnolencia. Hubo quienes los describieron como seres muy parecidos a los humanos, de una altísima frecuencia, luminosos y bellísimos. Al día siguiente de la ceremonia, los maestros comentaron los indicios de estas presencias. Algo muy importante había ocurrido esa noche: un encuentro en la montaña con los "hermanos de las estrellas" y la instauración de nuevos códigos genéticos. ${ }^{7}$

Otro de los maestros-guías de la red, mezcla de monje tibetano y sacerdote maya, vino a San Cristóbal en junio de 2010. Durante sus enseñanzas indicó que habremos de salvarnos por una nave. Una nave donde subirán todos aquellos que hayan sido capaces de elevar su frecuencia y quienes fundarán la nueva era. Nos instó a que oráramos para propiciar la creación de esta nave energética, invisible. La descripción de esta nave era muy cercana a las imágenes de los ovNIs. Una imagen similar al mito del arca de Noé que será comandada, ahora, por un extraterrestre.

Con estos ejemplos hemos querido destacar la importancia, la velocidad con que crece, el despliegue y la complejidad de este proceso imaginativo. Los documentos y videos que circulan por Internet son generalmente canalizaciones de aquellos que nacieron con el don de transmitir los mensajes de extraterrestres, mensajes equiparables a los de ángeles y arcángeles considerados como pobladores de otras dimensiones del universo. Todos, seres divinos y seres estelares venidos de otros planetas y galaxias, pueden moverse por distintos dimensionales, es decir, entre universos paralelos que coexisten en el multiverso. Los extraterrestres benevolentes son tomados, además, como portavoces de mensajes divinos. Estos discursos suelen ser descriptivos y controversiales. En las líneas que siguen los exponemos.

\section{Rejilla cósmica: Internet en la red}

Con frecuencia hemos escuchado decir a los integrantes de esta red que la Internet, el cine, la radio, la música, están siendo usados por los extraterrestres y, en general, por los seres de luz, para difundir los mensajes y fortalecer el trabajo de unión, de fortaleza del grupo. Películas como iY tú qué sabes?, Avatar y, una de las más populares en este circuito de la red, Creer es crear, por ejemplo, son consideradas como un resultado de una labor luminosa. Pero, además, existen productos más inmediatos, como textos o videos que circulan muchas veces por You Tube. Algunos de estos videos pretenden ser mensajes directos de extraterrestres. El comandante de la Confederación Galáctica, Ashtar Sheran, es quizá uno de los más populares de estos seres y es muy fácil acceder a su pródiga producción de mensajes que se encuentran en Internet con sólo escribir su nombre. 
Se habla de este personaje por lo menos desde 1955. Desde entonces, el protagonista ha sido inspirador para diversas agrupaciones, no todas New Age, y ha desatado una ola de canalizadores de sus mensajes.

Ashtar Sheran es considerado como un vigilante de la evolución de las razas inteligentes de la Vía Láctea; descendiente de Mikael —el arcángel Miguel-y Sananda - Jesucristo-, es entre otros cargos el comandante supremo de la Santa Alianza. El cometido de Ashtar es auxiliar a este planeta en crisis, y por tanto, es esa crisis el tema central de sus mensajes, así como la posibilidad de una transformación humana:

Habrá un gran alivio de las preocupaciones. Esto sucederá como resultado del aumento de la percepción del corazón. Los egos se encogerán y tendrán menos poder sobre el individuo. Esto acallará la cháchara mental. La mente local se volverá a conectar con la mente universal y las memorias de la Verdad penetrarán (Ashtar Sheran). ${ }^{8}$

Estos cambios repercutirán en la vida pública:

Cuando los medios de comunicación dejen de informar mentiras sobre la necesidad de conflictos armados, y cuando todos los corazones y las mentes de los que se hallan en la Tierra se hayan incrementado medio paso, el resultado será una suave finalización de la guerra y el surgimiento de la Paz Mundial. Las emisiones radiales de odio serán reemplazadas por hermosa música y la gente se hallará impulsada a balancearse de acuerdo a ella. Repentinamente todo "tendrá sentido" (Ashtar Sheran). ${ }^{9}$

El comunicado insiste en la transformación del mundo financiero:

Se retirará a todos los banqueros que han manejado sus imperios corruptos hasta la quiebra, a todos los abogados y funcionarios de justicia corruptos, así como también los doctores corruptos se habrán ido, arrestados o retirados. Los corredores de bolsa en Nueva York, Londres y Japón, como así también los de todo el mundo, verán el fin de la corrupción, dado que se detendrá a todos los negociantes criminales y se habrán ido. Las acciones serán congeladas hasta que las cosas hayan sido resueltas (Ashtar Sheran). ${ }^{10}$

E insiste, como lo hace en muchos otros comunicados, en la trasformación política y la solución de los problemas sociales:

En el gobierno estadounidense, los funcionarios gubernamentales que no dicen la verdad y que roban fondos y manipulan el sistema para su propio beneficio, serán arrestados y partirán. Solamente habrá un gobierno sombra a medida que las cosas serán encausadas. El aumento del amor y de la comprensión hará que la gente celebre los cambios en lugar de estar atemorizados.

Habrá una falta llamativa y repentina de preocupaciones entre la gente en todas partes. Los desempleados, los sin hogar,enfermosyhambrientos, repentinamentesesentirán bien de nuevo. La casi instantánea remisión del miedo tendrá un efecto profundo en la Tierra (Ashtar Sheran).."

Los hermanos de las estrellas están ahí, desde esta perspectiva, para ayudarnos a alcanzar este nuevo orden planetario. Pero, como lo explicamos más arriba, la batalla deberá librarse en contra de los grises, los illuminatis, quienes mantienen a los humanos como siervos de las sombras, de la negatividad.

Esta sería la apreciación más general de los propósitos y la clasificación de los extraterrestres entre los miembros de la red. Sin embargo, si un adepto a ésta quiere tener mayor información, con frecuencia son enviados a su correo personal no sólo mensajes, documentos o videos sobre estos seres, sino también algunos enlaces de Internet. Nos dimos a la tarea de seguir algunos de estos links y encontramos varias clasificaciones, algunas de ellas muy detalladas, 
mismas que provienen de canalizadores y contactados, Guerreros de Luz especialistas en el tema.

\section{Clasificación New Age de los extraterrestres}

Las minuciosas clasificaciones de extraterrestres se realizan considerando su ética y tendencias políticas. Estas clasificaciones contienen una evaluación de nuestro orden civilizatorio y las preocupaciones más apremiantes para ciertos sectores de la población que, como ya vimos, no son precisamente los más desposeídos.

Michael Salla (2004), quien es conocido entre algunos de los miembros de esta red como un especialista y canalizador de los extraterrestres, sugiere una división en dos grupos básicos: aquellos infiltrados en las élites gubernamentales o en los denominados gobiernos en la sombra, con quienes los extraterrestres han llegado a acuerdos y a colaboraciones conjuntas, y aquellos extraterrestres amistosos que no están del lado de los gobiernos y que, en esta cruzada, ayudan a preparar a la humanidad para su liberación.

La abundancia de estas razas extraterrestres y los acuerdos entre ellos y el gobierno en la "sombra" plantea la existencia de una élite que confabula y somete las instituciones políticas, financieras y los medios de comunicación. Son señalados, por tanto, como los autores de todos los problemas sistémicos del planeta y los más interesados en controlar y desmentir información que concierne a la existencia de vida extraterrestre. Alex Collier dice ser contactado por seres extraterrestres de la constelación de Andrómeda y se refiere a los Alpha Draconis o Alfa Draconianos, asociados a estos gobiernos "en la sombra", como sigue:

Han colonizado muchos sistemas estelares y han creado muchas razas por alteración genética de las formas de vida que encontraron. El área más densamente poblada de las sub-razas de draconianos es la constelación de Orión, Rigel, y el sistema de estrellas conocido como Capella. El sistema mental o la conciencia de la mayoría de las razas en esta región es el servicio a uno mismo y por ello siempre están invadiendo y manipulando razas menos avanzadas utilizando su tecnología para el control y la dominación. Los draconianos son la fuerza detrás de la represión de las poblaciones humanas, instalando sistemas de creencia basados en el miedo y jerarquías restrictivas (Collier, 2008).12

Los extraterrestres, según estas consideraciones, están entre nosotros desde siempre, participan en programas de intercambio de tecnología que promueven la cooperación militar y colaboran con los gobiernos "en la sombra" con investigación de armamento secreto para concentrar la riqueza y fomentar la desigualdad y la pobreza global. Son ellos quienes corrompen a las élites e instituciones, fomentan la violencia étnica y religiosa, la violación de los derechos humanos, el fundamentalismo religioso, el terrorismo, el tráfico de drogas y el crimen organizado.

Estas ideas son legitimadas o presentadas como una información proveniente de testimonios, en su mayoría, de militares "soplones". Se supone que son los más aptos para informar pues pertenecen a la institución más involucrada no sólo en los contactos con estos seres, sino en los secretos de Estado que guardan esta información. ${ }^{13}$ Parafraseando estos discursos, la información proviene, también, de los hermanos de las estrellas, aquellos extraterrestres benevolentes que están transmitiendo sus mensajes a la humanidad a través de los contactados o canalizadores. Grises o luminosos, los extraterrestres son imaginados como poseedores de una tecnología superior a la nuestra y con el poder de transfigurarse en humanos, de tal forma que son indistinguibles de nuestra especie. Pero la batalla que se libra no es exclusivamente terrícola. El complejo militar-industrial trasciende los límites de la Tierra. 


\section{Una guerra estelar. La tecnología como dominación}

Un argumento recurrente en los discursos sobre extraterrestres, de aquellos que se dicen ser contactados, es que la dominación ejercida sobre los humanos por parte de los grises o draconianos se debe a su superioridad tecnológica. En una entrevista realizada a Alex Collier en 2008, éste plantea que los Renegados de Zeta Reticulum (una de las razas estelares) han sido capaces de manipular a los gobiernos más poderosos (sobre todo los Estados Unidos) debido a su tecnología, dos mil quinientos años más avanzada que la nuestra:

...hay un factor más, éste tiene que ver con los seres humanos viviendo por el poder, y vendiendo a su propia raza por poder; vendiéndonos al resto de nosotros por su momento de gloria, por su privilegio de estar con los dioses, los cuales son extraterrestres. Esto es lo que es. Tienen tecnología que les puede llevar a la Luna, a Marte, para poder viajar en el tiempo, han vendido completamente a una raza nuestra historia; todo, por su momento de gloria (Collier, 2008).

Pero el problema no es exclusivamente terrícola, sino galáctico. Algunas razas cósmicas se han distinguido por su oscuridad y han tratado de imponer su orden, una de ellas es la raza de los draconianos:

Los draconianos son tremendamente inteligentes, muy psíquicos, son grandes constructores, pero son matones. Lo que les mueve a los draconianos es el control, controlar y dominar a otros, y debido a que no hay ninguna raza en nuestro Universo que sea capaz de combatirlos y hacerlos desaparecer, no tienen por qué escoger estar del lado de la luz. Han escogido la polaridad opuesta a la de la luz, y son un difícil escollo, son duros de eliminar o hacen esta situación difícil en nuestro Universo. Los draconianos han manipulado muchas civilizaciones de nuestra galaxia, y también son responsables de la guerra de 600.000 años que prácticamente terminó con la especie humana en nuestra galaxia, y no muestran ningún tipo de remordimiento por ello (Collier, 2008).

Junto con los draconianos, otras razas extraterrestres están sembrando negatividad en la galaxia, sometiendo e implantando su orden. Nuestra historia sobre el planeta, así como nuestros sistemas sociales son explicados como un implante:

...los del Grupo de Orión (los Grises de Zeta Reticuli 2) han sido genéticamente manipulados, y han entrado profundamente en el sistema de creencias de los draconianos, así que están cargando este tipo de energía, con las agendas o intenciones de éstos, además de sus propias agendas o intenciones como especie. Los Grises también han sido manipulados y controlados por los del Grupo de Orión, así que existe una jerarquía de control sistemática que se ha establecido. Este sistema es muy común entre los grupos de ET's no benevolentes o regresivos, donde existe una sociedad de clases; trabajadores, guerreros, administradores, sacerdotes, y luego la jerarquía o realeza. Cuanto más abajo en la jerarquía estás, peor eres tratado. Aquí en nuestro planeta tenemos mucha historia sobre esto, y este sistema ha sido enseñado por estos mismos extraterrestres. Incluso los Pleyadianos eran en un pasado parte de este sistema de creencias y de estructura social (Collier, 2008).

Ante los problemas de involución que han creado los extraterrestres malevolentes en la galaxia, se han unido varias razas planetarias y han formado un concilio:

El Concilio de Andrómeda es un organismo político representado ahora por 133 razas, culturas y sistemas planetarios diferentes, hay 1.200 sistemas y razas 
planetarias evolucionando que podría formar parte del Concilio de Andrómeda, pero no todas participan. Podría compararse con la ONU, pero no es una Organización de las Naciones con un itinerario político, sino con un objetivo espiritual y de evolución (Collier, 2008)

En la entrevista, Alex Collier destaca que el Concilio de Andrómeda fue creado tras una inmensa guerra, la Guerra de Orión, que duró 600 mil años en nuestra galaxia, protagonizada por los reptilianos y los humanos, diseminados en varios planetas de la galaxia. Tras esta guerra se formaron dos grupos políticos: el Grupo de Orión y el Concilio de Andrómeda; este último está formado por humanos diseminados por todo el universo y tiene como propósito compartir su conocimiento, apoyar con su sabiduría, enseñar el amor incondicional y ayudar a evolucionar a todas las formas de vida. Porque los habitantes de Andrómeda, a diferencia de los draconianos, tienen un equilibrio entre su tecnología y su nivel espiritual. Espiritualmente, están 4,700 años más avanzados que nosotros y 5.000 años más evolucionados a nivel tecnológico. Utilizan la tecnología para evolucionar espiritualmente, no para las guerras. ${ }^{14}$

\section{Los extraterrestres benevolentes}

Cuando entremos nuevamente en el estado del corazón viviente, y comencemos a soñar del modo que lo hacíamos hace millones de años, nos daremos cuenta de que podemos cambiar cualquier cosa.

Melquizedek

Como lo mencionamos más arriba, estas ideas sobre la naturaleza de los extraterrestres son motivo de grandes polémicas. Melquizedek, por ejemplo, es otra de las "voces" extraterrestres, quizá una de las más escuchadas por la red. Al igual que Ashtar Sheran, Melquizedek tiene sus canalizadores o contactados y sus mensajes circulan profusamente entre los integrantes de la red. Melquizedek es un ser estelar benevolente, que se presenta como un canal de la energía crística. Al igual que muchos otros mensajeros de las estrellas, Melquizedek afirma que la tierra no es nuestro planeta originario:
Nuestro espíritu es infinitamente viejo: no ha habido un tiempo en el que no hayamos existido, como nunca habrá un tiempo en el que no existiremos. Lo que quiere decir que todos vinimos de alguna otra parte. Somos ET's. Los delfines también lo son; vinieron de Sirio con las ballenas. Muchos pleyadianos están aquí desde hace mucho. Gente de Aldebarán [...] y de todos otros lados se han encontrado aquí (Melquizedek, 2007). ${ }^{15}$

Sus mensajes van todos dirigidos a los Guerreros de Luz para prepararlos ante los cambios de frecuencia que sufrirá nuestro planeta. El consenso es que somos los protagonistas del fin de un ciclo caracterizado por el horror de las guerras, el sufrimiento, y personajes también capaces de una transformación radical.

Como miembros de la Familia de Luz habéis nacido con la capacidad de transformar la realidad. Tenéis que crear un sistema de creencias que os permita hacerlo, puesto que vuestra mente está estructurada para evolucionar y formar vuestras experiencias según lo que vosotros solicitáis, sin tener en cuenta desde qué plataforma de paradigmas partís (Marciniak,2011).

Pero Melquizedek difiere de forma radical en esta idea de un universo convulsionado por las polaridades. Sus discursos insisten una y otra vez en la unidad del universo y critica seriamente esta insistencia en la dualidad entre el bien y el mal. En sus propias palabras:

“...las ideas de la guerra de las galaxias sólo son un miedo mental de los humanos. [...] Tenemos la idea de que en el Universo están peleando unos contra 
otros, vamos a descubrir que esto no es cierto, que en realidad el Universo es un ser vivo, consciente, y muy, muy viejo, que se ocupa de lo que le ocurre a sí mismo de muchas maneras" (Melquizedek).

Melquizedek también difiere en esta sobrevaloración de la tecnología y pone por encima de ella el avance espiritual:

Las 250,000 culturas que mencioné son las que vinieron usando sus vehículos. Eso quiere decir que es la forma más baja de vida en el universo, que ya vinieron aquí. Ustedes no ven al Arcángel Miguel viajando en una nave espacial, no la necesita, puede estar en cualquier parte donde quiera estar, los más altos niveles de conciencia pueden simplemente estar donde quieran estar (Melquizedek).

Aunque el desacuerdo respecto a esa dualidad del universo y, en particular, sobre la naturaleza de los extraterrestres, está latente en los discursos de las voces "venidas de las estrellas", existe la convergencia de que, por lo menos, muchos de ellos son nuestros aliados. $^{16}$

En síntesis, se plantea que los extraterrestres benevolentes nos asisten en la construcción de un sistema ecológico idóneo para la evolución de la humanidad, nos comparten información técnica y nos inducen a transformar nuestra cultura científica, nuestros sistemas de justicia social, nos enseñan a hacer un uso responsable de la tecnología y a integrarla como parte de un desarrollo espiritual. Lo que debe cambiar en nuestro planeta, según estos mensajes, es el estado actual de los derechos universales, de los sistemas políticos, de la educación, de la corrupción y manipulación de los gobiernos y élites. Se insiste en la protección del medio ambiente, en la importancia de la biodiversidad y la biosfera, pero sobre todo en la trasformación de los paradigmas científicos y el desarrollo de tecnologías alternativas.
Nuestro propósito hasta aquí ha sido exponer, grosso modo, el dejo, el sentido de algunas de las imágenes nucleares de este trabajo de la imaginación. Ensueño que por momentos tiene el acento de una novela o película de ficción, pero que, como expondremos en los siguientes apartados, constituye una deslegitimación del orden actual y una potencia de movilidad social.

\section{La red como metáfora}

El complejo mundo que constituye este imaginario con humanos, extraterrestres, tecnologías y divinidades en interacción es un verdadero en-redo, una red inmensa cuya fortaleza se encuentra en los maestros, seres ascendidos, extraterrestres, divinidades, canalizadores, niños "índigo y cristal", ${ }^{17}$ pero sobre todo en el "ejército raso": los Guerreros de Luz. Se trata, retomando una metáfora recurrente entre ellos, de un tejido cósmico:

Debo decir, sin embargo, que en este trabajo que se viene desempeñando desde el principio de los tiempos, cada uno de los que leen estos escritos tiene un rol que debe cumplir. A cada uno de ustedes le corresponde un hilo dentro del gran tejido cósmico que todos venimos tejiendo. Somos una gran familia que hemos venido creciendo en número y en conciencia (Melquizek, 2007).

El extraterrestre, de esta manera imaginado, funge en este caso como una alteridad, como un punto de ruptura epistemológica desde el cual se juzga el mundo en el que vivimos. Por obra de la libertad de la imagen, la irrupción conlleva una evaluación del estado actual de nuestras instituciones, la esperanza de un cambio, el despliegue de un paisaje distinto, recreado. Ahora bien, ¿cómo sueña ser esta red? Se sueña opuesta a esa sociedad piramidal construida con el sufrimiento generado por los actuales líderes políticos, financieros, religiosos. Se imagina como una red benevolente, tejida por seres de luz, amorosos y liberados, capaces de crear 
un mundo mejor, más justo para el planeta y para el universo. ${ }^{18}$

Las imágenes de red elaboradas por los Guerreros de Luz indican el trabajo de lazo, de congregación social a partir de una espiritualidad que, por obra de la imaginación, trasciende no sólo barreras nacionales sino "interplanetarias" y muchos de los límites de aquello que concebimos como real.

La popularidad del término red ha rebasado los intereses académicos o científicos. Los mismos integrantes de aquellas que nosotros definiríamos como redes emplean este término para dar cuenta de su propio universo contemporáneo e interconectado; se afanan en la construcción de un lenguaje, de un imaginario que dé cuenta de sus propias formas de interacción, pero además, trabajan para construir metáforas inspiradas en este concepto y, al mismo tiempo, crear formas de acción grupal, lazos e interacciones. Considerar este trabajo de la imaginación, traducirlo a nuestro lenguaje académico, puede ayudarnos a comprender cómo funcionan estas interconexiones o redes.

En este caso, los mismos integrantes se conciben como una extensa red de espiritualidad que utiliza la Internet y todos los medios de comunicación a su alcance para crecer rápidamente. Su intención es envolver, como si se tratara de extender una maya de pesca, al planeta entero y aun más allá, al universo.

Debido a que se considera que todo en el universo contiene un único patrón energético, el proyecto es crear un planeta luminoso, de alta vibración capaz de comunicarse con seres hondamente evolucionados. Si existe una interconexión energética, un mismo patrón energético para toda la materia, como lo plantea la física cuántica, entonces los humanos podemos ser considerados parte de una totalidad galáctica. Por esta razón, gran parte de este imaginario incluye ideas de que en este proceso de transformación los humanos no estamos solos, sino que hay una Confederación Intergaláctica. Esta inmensa red intergaláctica, inter humana-divina, inter vivos-muertos, es imaginada como una telaraña cósmica. Una de nuestras informantes nos comentó al respecto: "Estamos tejiendo esta telaraña cósmica. Cada maestro, cada niño índigo o cristal que nace con dones especiales, cada arcángel, cada dios o diosa está en cada uno de los nudos donde se entrecruzan los hilos de esta red, para fortalecer el tejido".

Los Guerreros de Luz conciben la comunicación entre diferentes dimensiones o realidades como un trabajo en red. El manejo y el conocimiento de la energía son la propulsión de la labor en red que pretende, unas veces, envolver al planeta, otras, al universo mismo. La metáfora de red es tan importante para este imaginario que no sólo la usa para designar la forma de asociación de sus integrantes. Es usual durante los rituales imaginar que con la energía generada y trasmutada grupalmente, cada uno de los participantes contribuya a envolver al planeta y a la humanidad en una red de luz, por ejemplo. Una de las maestras de la red dijo durante uno de los rituales: "la rejilla de luz ya está formada, fortalezcamos la red. Salgamos afuera del planeta y nos unamos a esta red". Aquí la imagen de red es la de una rejilla.

Y la red, en permanente crecimiento, no cesa de rehacerse, de en-redarse más allá de cualquier frontera política, económica, cultural. Más allá, incluso, de las fronteras que atraviesan el planeta y los límites entre la imaginación y lo real. Una "realidad" puesta aquí, con toda intención, entre comillas.

\section{Una realidad re-imaginada}

Este imaginario sobre los extraterrestres no es, como lo hemos intentado dejar ver, de ninguna manera azaroso. Constituye la imagen medular de esta utopía, como también lo es la de mundos o dimensionales paralelos a nuestra realidad evidente, considerada como la tercera dimensión. El nuevo orden se instaurará sobre estas otras realidades, con las cuales la humanidad aprenderá a convivir y comunicarse de manera pacífica y armónica.

¿Cómo establecer la otredad en este caso, cuando la humanidad comparte las mismas o semejantes 
problemáticas? El otro ya no puede ser un otro humano, pues la humanidad entera parece atrapada en la misma cárcel. Al otro hay que crearlo, imaginarlo, traerlo de otra parte. Y tiene que ser un otro que trascienda la talla de nuestros problemas, seres celestiales humanizados, más avanzados, más civilizados y evolucionados. Si en nuestro planeta no existe ya la posibilidad de imaginar un espacio utópico, un lugar inexistente debido a que conocemos no sólo todos sus rincones, sino porque hasta el último rincón pareciera ser parte del sistema-mundo, la imaginación de los Guerreros de Luz ha encontrado un no-lugar, una otredad en el cosmos. El nuevo proyecto se funda en una confederación galáctica, universal; pero también, en el surgimiento de lo que ellos consideran un "nuevo paradigma". Este "paradigma" admite, de entrada, la existencia de múltiples realidades y de tan diversos como válidos modos de conocimiento, idea que parece provenir de la física cuántica, que plantea la existencia de universos paralelos, es decir, de múltiples dimensiones o realidades más o menos independientes, como partes de un multiverso.

Se dice que muchos de los maestros o guías, dinamizadores de la red, provienen de otras realidades, a veces también llamadas dimensiones. En la quinta dimensión mora Jesús, quien se convierte en Cristo Cósmico; los mayas, en mayas cósmicos; la serpiente emplumada, en serpiente de luz cósmica, y así sucesivamente. Cada una de estas deidades cósmicas son consideradas maestras, canalizadoras de luz. Sobre el planeta existen varios canalizadores humanos de sus enseñanzas, también hay canalizadores de las enseñanzas de Cristo, de las vírgenes, los ángeles, San Germain, los lemurianos, los cirianos, por citar algunos. A través deestos canalizadores llegan los mensajes de deidades y maestros, mensajes, importantísimos para los Guerreros de Luz, porque provienen de seres que están dirigiendo al ejército en este tránsito hacia la nueva era. Son los seres que iluminan el momento más oscuro por el que atraviesa la humanidad.

Los mensajes pueden ser enviados por ángeles o seres que moran en otras dimensiones, pero predominan los mensajes enviados por el Cristo Cósmico o por extraterrestres que encarnan el mensaje crístico. Se considera que la encarnación de esta energía universal del amor está sucediendo en todo el planeta y es similar a la encarnación del Cristo Cósmico que vivió Jesús en su propio cuerpo. En sus mensajes, el Cristo Cósmico hace referencia a la unión galáctica. Jesús se convierte, de este modo, en uno de los maestros cósmicos más escuchados de la Nueva Era.

\section{Otra concepción de la realidad}

\begin{abstract}
Nosotros sólo creamos lo imaginario desde donde vosotros evolucionáis. Nuestra intención es asistiros en la creación de una nueva visión, una visión que os inspirará a vivir y amar en el planeta Tierra.
\end{abstract}

Lospleyadianos

Este universo poblado por ángeles, dioses y seres intergalácticos forma parte de una realidad en la que se interconectan múltiples realidades. Todos formamos parte de ella y podemos, desde esta perspectiva, comunicarnos e interactuar en forma de red. Esta manera de imaginar lo real tiene que ver, como ellos lo plantean, con el surgimiento de un nuevo paradigma de conocimiento. Este paradigma cuestiona nuestras formas actuales de producir el saber, así como las aberraciones a que nos ha conducido, sugieren, la racionalidad dominante. El nuevo paradigma cuestiona nuestras nociones de realidad. Son estos esquemas de nuestra percepción de lo real los que han contribuido a la separación, a la dispersión, a las fronteras entre culturas, entre países, entre humanos, así como entre humanidad y sacralidad. Nuestra realidad es limitada; por lo tanto, lo que proponen es la ruptura de estos esquemas mentales y emocionales que componen nuestras formas de imaginarnos lo real.

La realidad, según una de las imágenes centrales de este imaginario, es energía, y el nuevo paradigma centra su interés en el conocimiento de la energía 
que en principio admite la existencia de una energía universal, de una conciencia que satura el universo. Debido a la idea de unidad, cada ser, cada creación constituye un correlato del cosmos. Cada individuo es en sí mismo humanidad entera, universo. Cada cuerpo narra al cosmos. El campo energético es holográfico, es decir, cada parte contiene información del holograma completo, es decir, existe una conectividad instantánea entre la parte y el todo.

El ser humano es considerado un complejo cuántico, algo así como una coherencia comportada por cuerpos sutiles de luz y, además, de sonido. Se considera que las moléculas, todas formadas por quantums, por luz, vibran al unísono y se comportan como una súper-molécula, compartiendo un único patrón energético. Debido a que existe un único y coherente patrón energético para todos los seres vivos y para todo cuanto existe en el universo, el ser humano tiene la capacidad de conexión e interacción con el universo. La salud, la alegría, el bienestar, el equilibrio emocional, dependen del grado y la calidad de la conexión con esa energía universal.

Una gran parte de los procesos metafóricos de esta utopía se han inspirado en la física cuántica. El salto cuântico, por ejemplo, consistiría en este caso en una evolución no progresiva, en una transmutación similar a la que ocurre con los quantums. También se reelabora la idea, alimentada por esta fuente, de que todo cuanto existe en el universo es luz. El quantum es la unidad más pequeña que constituye la luz. Desde este punto de vista, todo es energía; y la materia, luz condensada. La luz es entonces considerada como una sustancia universal. Los seres de luz, los trabajadores de la luz, los Guerreros de Luz y, en suma, el ejército de luz, asumen esta dimensión luminosa: el ser humano está también formado de esta misma sustancia universal: luz pura y radiante.

De la física cuántica proviene, entonces, una reformulación sobre las idea de realidad y conciencia. Pero esta unificación trasciende ampliamente a todo cuanto existe en el planeta Tierra, y alcanza a otras constelaciones o galaxias. El surgimiento - como ellos proponen - de un nuevo paradigma, tiene que ver con el conocimiento de la energía, con el desarrollo en el ser humano de una capacidad de conocimiento donde la intuición, la sensibilidad y el amor se convierten en capacidades que hay que desarrollar para aprender cómo funciona la energía, su propia naturaleza y la de las muchas realidades a las que nos remite.

Esta concepción de la realidad propicia imágenes afines de red. En ocasiones suelen emplear el término red para indicar el trabajo conjunto de personas que interactúan, no necesariamente cara a cara, en el trabajo espiritual para transformar la humanidad y sus instituciones, condición sine qua non para lograr el salto cuântico y el inicio de una nueva era. Cuando se refieren a la red, la evocación es de fuerza, de unión por un propósito, aun si quienes son parte de ella no se conocen. La fuerza está en el trabajo conjunto, espiritual, para lograr el paso a la siguiente era.

\section{Consideraciones finales}

El que tiene imaginación, con qué facilidad saca de la nada un mundo.

Gustavo Adolfo Bécquer

Por sus formas de asociación, la metáfora de red parece bastante acertada para dar cuenta de las tácticas y dinámicas de congregación empleadas por los Guerreros de Luz en esta cruzada. Los miembros de la red emplean metáforas para referirse a la naturaleza de sus lazos, a su forma de actuar, así como al trabajo de la imaginación y a la diversidad de hilos que la tejen y cambian en un bordado infinito, siempre redibujado. Esa red se construye en el imaginar mismo, tarea a veces solitaria, a veces grupal. Cada imaginante, con sus diversas rutas y búsquedas, cada grupo, contribuyen a la configuración del tejido multiforme de este proceso imaginativo. 
La potencia de los Guerreros de Luz es planteada como la imaginación o el ensayo de un cosmos distinto, de una reinvención de los lazos sociales; es soñada como una sociedad en red. Una red que se quiere no antropocéntrica y se imagina entrelazada por lazos tanto humanos como interplanetarios, tanto tecnológicos como divinos. Los extraterrestres "oscuros" aparecen en este imaginario como los responsables de un orden civilizatorio que ya no se desea, un orden que reproduce jerarquías y relaciones de poder piramidales. En los discursos sobre los extraterrestres, emitidos por los Guerreros de Luz, lo que se pone en tela de juicio es el mundo tal y como está. La clasificación de estos seres obedece siempre a su ética, a su tendencia política. Los tipos de extraterrestres constituyen, de entrada, un análisis social que deslegitima el ordenamiento del mundo, donde se manifiesta un malestar por parte de aquellos que sueñan con un mundo mejor.

Si comprendemos la utopía, como lo propone Ricoeur, como inauguración de otros mundos, como ruptura epistemológica o no-lugar desde el cual se piensa el orden imperante, como ese desplazamiento que permite imaginar otras posibilidades de ordenamiento, la imaginación desplegada en torno a los extraterrestres por parte de los Guerreros de Luz, pone al día una modalidad de la esperanza, es utópica.

La idea central debe ser la de ningún lugar implícita en la palabra misma y en la descripción de Tomás Moro. En efecto, a partir de esta extraña extra-territorialidad espacial -de este no lugar, en el sentido propio del término, puede dirigirse una mirada nueva a nuestra realidad, en la cual desde ahora ya nada puede tomarse como adquirido.

El campo de lo posible se abre desde ahora más allá del ámbito de lo real. Este campo es el que jalona las otras maneras de vivir mencionadas antes. La cuestión es saber si la imaginación podría tener un papel constitutivo sin ese salto al exterior. La utopía es el modo según repensamos radicalmente lo que son la familia, el consumo, el gobierno, la religión, etcétera. De ningún lugar brota el más formidable cuestionamiento de lo que es. La utopía aparece así, en su núcleo primitivo, como la contrapartida exacta de nuestro primer concepto de ideología como función de la integración social. La utopía, en contrapunto, es la función de la subversión social (Ricoeur, 1991: 214).

Y aquí utopía es el no-lugar, el sitio de ninguna parte, ubicado en el universo, fuera del planeta, habitado por todo cuanto pueda imaginarse como parte del mundo de las estrellas, incluidos extraterrestres, quienes en este caso parecieran fungir como un tipo particular de profetas, tal como fueran definidos por Weber. Los extraterrestres son imaginados como intermediarios carismáticos entre la humanidad y la divinidad, tienen la misión de comunicar revelaciones divinas a los seres humanos. Esa nueva sociedad, ese renovado mundo anunciado en sus mensajes, la interpretación de la historia, tiene el tono de una profecía. Ya Weber había señalado ese lado subversivo de los profetas y brujos, quienes se mueven fuera del sacerdocio o de la institución. Su poder estriba, como lo ha señalado Bourdieu repasando a Weber, en su carisma y en el recurso de la palabra portentosa que no respeta la rutina, ni la sistematización de la ortodoxia.

Hemos insistido, a lo largo de este estudio, en la importancia que reviste el trabajo sobre el lenguaje por parte de quienes integran este Ejército de Luz. Pareciera que se afanaran, tal como lo planteó Wittgenstein (2002), en la construcción de un nuevo juego de lenguaje para, de ahí, construir nuevos mundos. ${ }^{19}$ Y esos discursos, puestos en boca de pretendidas presencias extraterrestres, instan a la creación de palabras, de imágenes aptas para la transformación. Tal cual profetas, las voces extraterrestres ofrecen un sentido unitario, renovador y vital. Porque como lo sugiere Bourdieu:

Durante tanto tiempo como la crisis no haya encontrado su profeta, los esquemas con los cuales se 
piensa el mundo invertido son todavía el producto del mundo a invertir. El profeta es el que puede contribuir a realizar la coincidencia de la revolución consigo misma, operando la revolución simbólica que requiere la revolución política (Bourdieu, 2006: 83).

Bourdieu señala, además, la capacidad del profeta para generar discursos capaces de expresar lo innombrable, pues lo nombrable está ya en boca de quienes han seguido un sacerdocio institucionalizado.

Melquizedek, una de las voces supuestamente extraterrestres expuestas en este artículo, incita a los Guerreros de Luz a renombrar, a soñar, a imaginar, a creer que se puede lograr un cambio. La imaginación pasa a ser la mayor potencia de la red; la acción, su lazo más poderoso. Los nodos, las voces que dinamizan la red impulsan y alimentan este trabajo imaginativo y creativo. En uno de los tantos textos que circulan por Internet, firmado supuestamente por los pleyadianos, esto es planteado directamente:

Cuando os abráis a vuestra mayor identidad, sed receptivos y estad dispuestos a ir más allá de vuestras fronteras, pues es por esto por lo que estamos. Deseamos implantar nuevas imágenes en vuestra mente, imágenes que os lleven luchando más allá (Marciniak, 2011).

La creación comienza así por el lenguaje, es el lenguaje mismo el sujeto de la trasgresión. Es con un lenguaje metaforizado que se pon en tela de juicio las religiones, así como lo que se considera una cultura científica devota al sistema, al servicio de las guerras, la tecnología y el saber desacralizado, poco respetuoso de otras alternativas de conocimiento.

Estos grupos plantean entonces un nuevo paradigma imaginado como una inmensa red donde caben todas las posibilidades de realidad y discernimiento. Inspirados en la física cuántica, se afanan en la construcción de este modelo capaz de dar cuenta de la naturaleza de la energía y de la luz. La luz, así, es la inspiradora nodal de los procesos metafóricos, del lenguaje utópico de esta red. El mismo nombre de la red se inspira en la luz: los Guerreros de Luz, quienes forman parte de un ejército de luz. Las formas de imaginar la vida extraterrestre tienen que ver con imágenes de red, de luz y sombra. De esta manera son concebidos como una gran familia:

La Familia de Luz, a la que vosotros pertenecéis, procede de un linaje de conciencia. ¿Quiénes son la luz? ¿Quién posee la luz? ¿Qué hay más allá de la luz? Sentid esto por un momento y daos cuenta de que a vuestra mente humana le encanta fabricar mitos, pequeñas historias y cuentos de hadas en lo referente a los verdaderos sucesos del cosmos. Vuestra versión es minúscula en relación a lo que existe de verdad. Por eso os pedimos que cambiéis radicalmente vuestras historias y comencéis a imaginar versiones mucho más amplias de la existencia.

La Familia de Luz es un conjunto de entidades codificadas que trae la información a este planeta. La codificación está dentro de cada individuo. Una vez dispuestos a cuestionar y mirar más allá de las actuales interpretaciones de la realidad, se os guiará para crear formas de pensamiento que hagan que se disparen vuestros códigos (Marciniak, 2011).

Porque la luz, información pura, "es la única capaz de alumbrar la oscuridad, la tenebrosidad de nuestra actual civilización", la metáfora es especialmente efectiva para proponer formas alternativas de existencia. Junto con los extraterrestres, en este caso antropomorfizados, desempeñando el rol de profetas, los Guerreros de Luz intentan constituirse en un otro, en una alteridad apta para soñar despierta e interactuar con las divinidades en una red infinita, en una telaraña cósmica, digna de una utopía que quiere irrumpir en la viscosidad de nuestro presente y abastecerse de un lenguaje crítico para reconfigurarlo. 


\section{Notas}

${ }^{1}$ Un adepto de la nueva era es identificado como aquel cuya individualización exacerbada le ha permitido adquirir las destrezas de composición de una religiosidad que sobre todo se niega como religiosa y que responde a la lógica del remiendo de diversos símbolos extraídos de disímiles orígenes y de la adopción de conocimientos sobre la salud y la sacralidad provenientes de distintas culturas o tradiciones. San Cristóbal de las Casas se ha convertido en un sitio privilegiado para estas experiencias New Age, especialmente por la presencia de culturas autóctonas consideradas mayas y el entorno de resistencia (altermundismo, zapatismo, feminismos, etcétera). La cultura maya es la gran inspiradora del trabajo imaginativo New Age. Vid.Ruiz Torres et al., 2011, Teisenhoffer, 2008, Champion, 1991, Heelas, 1993, Carozzi, 1998, 2003.

${ }^{2}$ Es importante destacar que al referirnos a esta red como Guerreros de Luz no se está considerando como un grupo con lindes precisos. Como la red es extensa y difusa, la manera de auto nombrarse y auto concebirse presenta variaciones, pero su identidad se construye siempre a partir de nociones relacionadas con la luz: "guerreros de luz", "caballeros de luz", "seres de luz", "ejército de luz", por mencionar algunos. Hemos decidido retomar el término Guerreros de Luz, pero imaginándolos como una asociación más que como una "sociedad" fácilmente demarcable.

${ }^{3}$ Los androides, humanoides, cyborgs, quedan fuera de este imaginario New Age, aunque en la ciencia ficción también aparecen antropomorfizados, con apariencia, actitudes y emociones humanas. Las formas en que son imaginados los extraterrestres por los Guerreros de Luz tienden más, no sólo hacia su humanización, sino sobre todo hacia la divinización de estos seres venidos del universo y no a partir de una creación tecnológica.

${ }^{4}$ El concepto que manejamos de utopía está lejos de su acepción peyorativa. Destacamos, por el contrario, la fuerza de la utopía como motor social, su poder de cuestionamiento, su valía para imaginar otras formas de ser humanas y sociales. El supuesto que guía esta investigación lo retomamos de Ricoeur (1991): la utopía como ruptura epistemológica, como un no-lugar. Ese ninguna parte, que en este caso es imaginado dentro del ser humano mismo, pero también fuera del planeta, en el universo; constituye el lugar inexistente desde el cuál son inventadas nuevas maneras de decir las cosas, nuevas maneras de pensarlas, otras formas de imaginar el mundo.

${ }^{5}$ Entendemos por imaginación la acción de renombrar, tal como lo propone Paul Ricoeur, a través de metáforas vivas (1991). En Modernidad desbordada (2001), Apadurai ya había señalado el despliegue de la imaginación como acción social en nuevos escenarios asociados a los medios electrónicos de comunicación, a las migraciones masivas y a la alta movilidad de las personas. Imaginarios que invitan a la acción colectiva y ponen en entredicho nuestras nociones de Estado, Nación y Frontera. Para este autor, la imaginación se ha convertido en un campo organizado de prácticas sociales, central para todas las formas de agencia y un componente fundamental del nuevo orden global (Apadurai, 2001: 44-45).

${ }^{6}$ De hecho, los mayas son considerados por este grupo como seres cósmicos, como un implante en nuestro planeta. Esta idea parece provenir de la imaginación popular reificadora del conocimiento astronómico de los mayas y de su mirada puesta sobre el firmamento.

${ }^{7}$ El tema del ADN genético y espiritual es uno de las recurrencias en los discursos sobre extraterrestres. En "Los códigos genéticos", Barbara Marciniak expone este asunto como sigue: "Ahora, algunos de éstos dioses creadores, como eran definidos sus trabajos, eran lo que se llamarían maestros genetistas, capaces de hacer algo de este material[...] los dioses creadores eran capaces, a través de sus jerarquías, de provocar, descubrir, unir y atar estas moléculas, las moléculas codificadas de identidad, de frecuencia, de cargas eléctricas, para crear vida. Y de las tantas civilizaciones sensibles, muchas, muchas, dieron 
su ADN de buena gana, para tener representación en su codificación, su ADN, en este planeta. Y los maestros genetistas se pusieron a trabajar, y diseñaron lo que se llamaría variedades de especies, algunos humanos, otros diferentes que los humanos, algunos que ustedes llaman animales, todo, jugando con las variedades de ADN que las civilizaciones sensibles contribuyeron para hacer este centro de intercambio de información, este centro de luz. Cuando hablamos de luz, estamos hablando de información. Aquéllos de ustedes que han tenido experiencias de permitir que la luz entre en sus cuerpos físicos, saben que, una vez se exponen a la luz, empieza a aumentar la cantidad de información. Así, el plan de la Tierra era grande... Y ya que estos dioses creadores no existieron en el tiempo como ustedes lo conocen, digamos que unos cientos de miles de años, unos cuantos millones de años, en sus términos, no era nada. Y se trajeron a existencia diferentes energías. Ha habido especies de hombres, sí, como ustedes, hombres parecidos a ustedes, cuyo ADN estuvo intacto alguna vez, que desarrollaron civilizaciones altamente evolucionadas", (Barbara Marciniak, "Los códigos genéticos" (consultado: en http://www.bibliotecapleyades.net/pleyades/esp_ pleyades_16a.htm).

${ }^{8}$ Canalizadores Beth y Mark, en: http://personal. globered.com/pakos-pagina/categoria.asp?idcat=174), [consultado: enero de 2010].

${ }^{9}$ Canalizadores Beth y Mark, http://personal.globered. com/pakos-pagina/categoria.asp?idcat=174. [consultado: enero de 2010].

${ }^{10}$ Canalizadores Beth y Mark, http://personal.globered. com/pakos-pagina/categoria.asp?idcat=174)[consultado: enero de 2010].

${ }^{11}$ Canalizadores Beth y Mark, http://personal.globered. com/pakos-pagina/categoria.asp?idcat=174, [consultado: en enero de 2010].

12 Algunos de los extraterrestres que conforman este grupo son los Grises Bajos (Zeta reticulum \& Orión), Grises Altos o Blancos (Orión), Reptilianos autóctonos (La Tierra), Draconianos Reptilianos (Alfa Draconis),
Sirianos (Sirio B), Anunnaki (Nibiru). Esta clasificación es propuesta por Michael Salla.

${ }^{13}$ El tono de los testimonios con los que se pretende legitimar este discurso sobre los extraterrestres suele ser como sigue: "Daniel Salter, otro "soplón" con una larga carrera militar que incluye un periodo en la National Reconnaissance Office (Oficina de Reconocimiento Nacional), afirmó que existe cooperación entre humanosextraterrestres en organizaciones clandestinas en la National Security Agency llamada Advanced Contact Intelligence Organization (ACIO). De acuerdo con información filtrada de otro "soplón" publicada en una conocida web llamada Wingmakers, afirma que la información de Salter es precisa, y que la ACIO está cooperando con un consorcio de extraterrestres para desarrollar sofisticada tecnología de viaje en el tiempo por posibles amenazas extraterrestres" (Salla, 2010, Tipologías de Extraterrestres).

${ }^{14}$ Esta potencialidad tecnológica también es atribuida a los intraterrestres, es decir, a vida inteligente que habita en las profundidades de la Tierra. La creencia en vida intraterrestre sostiene que en el interior de nuestro planeta se producen civilizaciones sabias, conocedores de la verdadera historia de la humanidad desde sus inicios. Se les atribuye una propensión hacia la oración y el trabajo interno. Algunos otros afirman lo contrario, es decir, que los intraterrestres pretenden dominar el mundo terrícola.

15 Melquizedek, 2007, "Un mundo superior": quinto llamado, en http://maestrosascendidosendataha.blogspot. com/2011/02/maquventa-melchizedek-un-mundosuperior.html, [consultado: febrero 13 de 2008].

${ }^{16}$ En la clasificación que hace Michael Salla, destaca un grupo de extraterrestres que no está vinculado con el gobierno. Se trata de extraterrestres amistosos dispuestos a ayudar a la humanidad en este periodo de transición. El grupo está conformado por telosianos (la Tierra), lyrianos (Lyra), veganos (Lyra), pleyadianos (las Pléyades), procyones (Procyon), tau cetianos (Tau Ceti), andromedanos (Andromeda), sirianos (Sirio 
A), ummitas (Ummo), Alfa Centauri (Alfa Centauri), arcturianos (Arcturus).

${ }^{17}$ Se supone que los niños índigo y cristal son parte esencial de este plan de transformación. Los niños cristal, se supone, son los transformadores, los rompedores de esquemas. A los niños índigo se les atribuye la función de pacificación, de la creación de lazos de amor.

${ }^{18}$ Hablar de red, en la actualidad, es referirnos a una gran variedad de objetos y fenómenos. El término red se usa en forma profusa en nuestro lenguaje cotidiano, académico y político. En las ciencias sociales el concepto de red ha sido reconocido, por lo menos desde los años 50 del siglo pasado, por sus bondades explicativas y descriptivas; por su capacidad de respuesta para diferentes problemas y en diversos dominios. Ahí donde se veían estructuras sociales, comenzaron a verse miembros de una colectividad, conjuntos de lazos e interconexiones. En términos muy generales, como categoría analítica, el concepto de red pretende proporcionar una explicación de los modelos de comportamiento social y su énfasis está en la interacción de los actores sociales; intenta proveer de modelos teóricos y metodológicos que den cuenta de la forma en que estos colectivos crean lazos y se interrelacionan. Más que afanarnos en una conceptualización, optamos por traducir lo que ellos mismos describen, insinúan o dejan entrever con este término, en el lenguaje de ellos, no siempre unívoco. Sus propias metáforas de red son comprensibles como parte de un imaginario más vasto, cuyas imágenes van formando ramificaciones de sentido.

${ }^{19}$ Wittgenstein ya había equiparado, en sus Investigaciones Filosóficas, el lenguaje de la filosofía tradicional con el de una enfermedad, y sugirió que si la causa de la enfermedad residía en el lenguaje había que encontrar la clave para su cura también en el lenguaje, la "lucha contra el embrujo de nuestro entendimiento por medio de nuestro lenguaje" (Wittgenstein, 2002: 109). Es decir, Wittgenstein defendía que cambiar la calidad de nuestra mirada, de nuestro lenguaje, era una condición ineludible para cualquier tipo de cambio.

\section{Bibliografía}

Apadurai, Arjun (2001), Modernidad desbordada, Dimensiones culturales de la globalización, Buenos Aires: F.C.E.

Bourdieu, Pierre (2006), "Génesis del Campo Religioso", en Relaciones núm. 108, vol. XXVII, México.

Carozzi, María Julia (1998), "La religión de la autonomía: Nueva era y nuevos movimientos sociales (o Nueva Era: la autonomía como religión)", ponencia presentada en VIII Jornadas sobre alternativas religiosas en América Latina, Sao Paulo.

Carozzi, María Julia (2003), "Ready to move along The sacralization of disembedding in the new age movement and the alternative circuit in Buenos Aires", en Civilisations, núm. 1-2, vol. LI, pp. 139-154.

Champion, Francoise (1990), "La nebuleuse mystiqueesoterique. Orientations psycoreligieuses des courants mystiques et esotériques comtemporains", en F. Champion y D. Hervieu-Léger, De la emotion en religion, Paris: Centurion.

Gadamer, Hans Georg (1977), Verdad y método I. Fundamentos de una hermenéutica filosófica, Salamanca: Ediciones Sígueme.

Gadamer, Hans George (2002), Verdad y Método II, Salamanca: Ediciones Sígueme.

Ricoeur, Paul (1991), Ideología y Utopía, México: Gedisa. Ricoeur, Paul (2002), Del texto a la acción, México: F.C.E. Ruiz Torres, Miquel, Martín López Moya, Efraín Ascencio Cedillo (2011), "Consumidores alternativos: turismo étnico y espiritualidad New Age en los procesos de reinvención del imaginario urbano en San Cristóbal de las Casas, México", en Llorenç Prats y Agustín Santana (coords.), Turismo y patrimonio. Entramados narrativos, Pasos, revista de Turismo y patrimonio Cultural, España. www.pasosonline.org. Teisenhoffer, Viola (2008), "De la 'Nebulosa místicoesotérica' al circuito alternativo”, en Argyriadis, Kali et all (coords.), Raíces en movimiento. Prácticas religiosas tradicionales en contextos translocales, México: El colegio de Jalisco, CEMCA, IRD, CIESAS, ITESO. 
Weber, Max (1994), La ética protestante y el espiritu del capitalismo, Barcelona: Península.

Wittgenstein, L. (2002), Investigaciones Filosóficas, Barcelona: Crítica.

\section{Referencias de internet}

Ashtar Sheran, canalizadores Beth y Mark, en http:// personal.globered.com/pakos-pagina/categoria. asp?idcat=174, [consultado: marzo 3 de 2010].

Entrevista al contactado Alex Collier y la raza extraterrestre de la Constelación de Andrómeda (2008), Documento producido de la traducción del inglés de la entrevista realizada por Rick Keefe en octubre de 1994 a Alex Collier, en http://www. exopoliticsspain.es/sp/entrevista-alex-collier.htm, [consultado: mayo 9 de 2011].

Michael Salla (2010), Tipologías de Extraterrestres, en http:// armonicosdeconciencia.blogspot.com/2010/03/michaelsalla-tipologias-de.html, [consultado: febrero 12 de 2011].
Canalizaciones de KROM, el Gran Sol Central de Nebadón. Canalizados por Ricard y Silvia, en http:// yosoy.mi-web.es/foro/krom-el-gran-sol-central-denebadon-08-03-09-tl848.html, [consultado: julio 13 de 2009].

Melquizedek (2007), "Un mundo superior": quinto llamado, en http://maestrosascendidosendataha. blogspot.com/2011/02/maquventa-melchizedekun-mundo-superior.html, [consultado: febrero 3 de 2008].

Melquizedek (2009), "Las nuevas energías espirituales de la Tierra", en Latinoamérica espacio Metratón, en http://hermandadblanca.org/2009/02/28/las-nuevasenergias-espirituales-de-la-tierra-en-latinoamericapor-drunvalo-melchizedek/, [consultado: mayo 8 de 2009].

Barbara Marciniak (2011), "Los códigos genéticos", en http://www.bibliotecapleyades.net/pleyades/ esp_pleyades_16a.htm), [consultado: abril 20 de 2011]. 